\title{
FUGINDO PRA OUTRO LUGAR: \\ O CLUBE DA ESQUINA, UMA POÉTICA DO MOVIMENTO
}

Lauro Wanderley Meller*

RESUMO: O artigo se pretende um passeio panorâmico pelos dois discos coletivos Clube da Esquina (1972) e Clube da Esquina 2 (1978), tendo como figuras de proa Milton Nascimento e Lô Borges. Compostos e lançados durante o período da Ditadura Militar (1964-1985), os discos trazem uma poética marcada pelo uso de metáforas e de outras figuras de linguagem que disfarçam críticas diretas ao regime. Neste paper, procedo a uma análise lítero-musical de algumas canções contidas nos dois discos, dando relevo às alegorias de deslocamento e de movimento, que além de fazerem uma crítica velada à situação política adversa sugerem um parentesco com o Fugere urbem dos poetas árcades.

PALAVRAS-CHAVE: Clube da Esquina; Canção de protesto; Música Popular Brasileira; Milton Nascimento; Lô Borges.

\section{Introdução}

No século XVIII, assistiu-se, no panorama das Belles Lettres brasileiras, ao ocaso do Barroco e à sua substituição pelo Arcadismo, escola que lhe era, em muitos sentidos, diametralmente oposta. Inspirado nos modelos clássicos da antiguidade e do Renascimento, o Neoclassicismo primava pela sobriedade (em oposição aos excessos barrocos) e tinha como características o pastoralismo, o bucolismo e o nativismo, numa busca por exaltar a

\footnotetext{
* Doutor em Letras pela Pontifícia Universidade Católica de Minas Gerais (Puc-MG). Professor Associado I da Universidade Federal do Rio Grande do Norte (UFRN).
} 
natureza e o homem em seu estado natural e puro, vis-à-vis do cenário urbano, que supostamente o corrompia.

O tom confessional é frequente nas composições árcades, bem como a espontaneidade de sentimentos - ainda que elas ocorressem num nível ficcional, ao lembrarmos que vários poetas árcades, como Cláudio Manoel da Costa e Tomás Antônio Gonzaga, pertenciam à aristocracia de Vila Rica (mais tarde Ouro Preto). Por sua inspiração clássica, tornouse comum a utilização de codinomes pastoris entre os poetas árcades (Dirceu, Lereno etc.), bem como as expressões latinas, como carpe diem (aproveitar o dia, dada a finitude da vida), Inutilia truncat (corte dos excessos, numa referência ao Barroco e em defesa da austeridade estética), Locus amenus (local ameno, longe da opressão dos centros urbanos) e, na mesma linha, Fugere urbem (fuga da cidade), termo cunhado pelo escritor clássico Horácio, e que se refere a deixar os centros urbanos e voltar-se a uma vida mais simples, no campo.

Se nos anos de 1700 o Fugere urbem original da Arcádia italiana era ressignificado pelos poetas do Brasil Colônia, na década de 1970 esse mote seria atualizado por um grupo de músicos da mesma Minas Gerais de Gonzaga e Cláudio, tendo como pano de fundo não a opressão do colonizador português, mas aquela de um regime militar que encontraria no governo de Emílio Garrastazu Médici (1969-1973) seu período mais brutal. Não por acaso o LP Clube da Esquina, lançado justamente em 1972, é recheado de alegorias e metáforas que traduzem os anseios de liberdade de um povo. Dentre essas, destacam-se as referências à viagem, à transitoriedade e ao deslocamento - no limite: Fugere urbem -, o que nos permite enxergar um parentesco, ainda que de viés, entre a poética do Clube da Esquina e a dos poetas árcades. Por isso, entendo aqui a obra do Clube da Esquina como engajada, embora não panfletária, isto é: apesar de engajada politicamente, não sacrifica o apuro estético em nome do compromisso ideológico.

Não deixa de ser paradoxal que canções que tão insistentemente tematizam a fuga e o deslocamento - e, por extensão, a transitoriedade e a natureza passageira dos fenômenos - tenham conquistado posição perene em nosso cancioneiro. Passo, então, à análise das canções. 


\section{Clube da Esquina (1972)}

Apesar de ter como figura de proa Milton Nascimento (que assina em parceira com Lô Borges o disco de 1972, e que é o autor principal do LP de 1978), o Clube da Esquina, como o nome indica, é uma entidade coletiva. Além dos já citados Milton e Lô, cumpre lembrar os nomes dos muitos compositores, letristas, arranjadores e intérpretes que participaram do projeto, como Beto Guedes, Márcio Borges, Fernando Brant, Tavinho Moura, Toninho Horta, Ronaldo Bastos, Murilo Antunes, Wagner Tiso, Nelson Ângelo e Flávio Venturini, sem falar nas participações de Danilo Caymmi, Paulo Jobim e Francis Hime (estes, no disco de 1978).

As trajetórias bastante distintas dos indivíduos que elaboraram esses dois projetos revelam-se na variedade de estilos e influências que ali convivem lado a lado. Mesclam-se elementos da música africana e dos festejos do interior de Minas, vocalizações e harmonias ao estilo dos Beatles, música andina, guitarras jazzísticas, linhas de baixo tributárias do rock progressivo inglês, cantos indígenas, modas de viola, bandolins e quartetos de cordas, tecendo-se assim uma diversificada paisagem sonora.

Dada toda essa heterogeneidade e a própria abrangência do corpus (21 canções do álbum duplo de 1972, e 23 do também álbum duplo de 1978), trabalharei por amostragem, tecendo comentários sobre algumas canções que salientem as características que pretendo destacar. Sem mais delongas, passo à faixa de abertura do disco de 1972: “Tudo o que você podia ser”, uma parceria dos irmãos Lô (Salomão) e Márcio Borges.

A canção se inicia com um singelo violão e com o canto suave de Milton Nascimento, que pouco a pouco vai se adensando e ascendendo melodicamente, disfarçadamente encorajando seu interlocutor a uma tomada de atitude. A insistente utilização de verbos no futuro do pretérito apontam para um ambiente adverso, em que os desejos do eu lírico são irrealizáveis: "Com sol e chuva / Você sonhava que ia ser melhor depois / Você queria ser o grande herói das estradas / Tudo o que você queria ser." 
Vocábulos como "segredo / medo" (“Sei um segredo, você tem medo") são também indicativos de um cenário político desfavorável e, neste particular, é notável a ocorrência da palavra "medo" nas canções do Clube da Esquina, tanto nos discos coletivos como nos LPs solo. Aliás, "medo" é palavra-chave nesta canção, e num verso em especial nota-se que é ela que confere uma resolução ao impasse do título: "Tudo o que você devia ser: sem medo". Não por acaso a curva melódica é descrita, nesta passagem, em movimento ascendente, culminando, justamente, na palavra "medo" (mas, reitero, neste caso transmitindo uma ideia de libertação: sem medo). Segue-se um solo de violão em terças, que nos traz à mente um ponteio de viola e, portanto, um ambiente rural. Assim, já estamos longe do ambiente urbano, numa atitude Fugere urbem tardia que, assim como nos poetas árcades, encontra na paisagem natural um refúgio.

Da paisagem rural sugerida pelo ponteio de viola na faixa inicial, passamos a um "Cais", segunda faixa do disco de 72 e uma das composições mais introspectivas dos discos em tela. Confirma-se a temática do deslocamento no título da canção, e novamente utilizase a técnica de se iniciar em registro grave, de modo que a voz pouco a pouco se eleve, numa melodia ascendente indicativa do desejo de libertação do eu lírico. Confirma-se, como na faixa anterior, a dificuldade em se concretizar o intento, uma vez que essas imagens de liberdade podem apenas ser "inventadas", isto é, sonhadas. Verifica-se, de resto, a ocorrência de verbos no condicional, sugestivas de que o eu lírico ainda está em busca dessa liberdade: "Para quem quer se soltar / Invento o cais / Invento mais que a solidão me dá / Invento lua nova a clarear / Invento o amor e sei a dor / De me lançar / Eu queria ser feliz / Invento o mar / Invento em mim o sonhador”. Na segunda estrofe, destaca-se o caráter coletivo desse discurso, seguido de uma metáfora para o exílio: "Para quem quer me seguir / Eu quero mais / Tenho o caminho do que sempre quis / E um saveiro pronto pra partir / Invento o cais / E sei a vez de me lançar”.

A antológica passagem instrumental que se segue (depois acompanhada pelo vocalise de Milton), é um misto de melancolia e firmeza: melancolia nos acordes dissonantes, 
amargurados, titubeantes, que vão e vêm na mão esquerda do pianista, indicando o dilaceramento e a instabilidade emocional do eu lírico, dividido que está entre o desejo de ficar e a necessidade de partir; e firmeza na pulsação inabalável da mão direita, precisa como um metrônomo, trazendo à tona a imagem de um exilado que, a passos largos, caminha sem se voltar.

Do saveiro de "Cais", embarcamos no "Trem Azul", terceira canção do disco, que constitui um contraponto otimista ao tom sombrio da canção anterior. Escrita em compasso quaternário e em andamento moderado, e recheada de acordes com sétima maior, o substrato musical sugere indefinição, com sequências harmônicas pouco usuais $(C \# 7+$, $\mathrm{A} 7+, \mathrm{E} 7+, \mathrm{F} \# 7+, \mathrm{C \# 7+,} \mathrm{A} 7+, \mathrm{E} 7+, \mathrm{D} 7+)$, inclusive rompendo com os esquemas de previsibilidade sucessivas vezes, tanto nas estrofes como na passagem para o refrão. Nas estrofes, essa quebra da expectativa se dá com o deslocamento do acorde de $\mathrm{F} \# 7+$ para o de D7+; na transição para o refrão, com a inserção do acorde de Eb7, que espraia a harmonia numa direção inesperada. Todo esse adiamento, confirmado na letra ("Coisas que ficaram muito tempo por dizer / Frases que o vento vem às vezes me lembrar / Coisas que ficaram muito tempo por dizer / Na canção do vento não se cansam de voar”), só se resolve no refrão, quando o eu lírico propõe que seu interlocutor "pegue o trem azul", numa viagem em que finalmente o sol brilha, não apenas no céu, mas na "sua cabeça", quando ele finalmente poderá se expressar livremente.

"Nuvem Cigana", ouvida aqui numa primeira versão (a canção ganharia nova interpretação em LP solo de Lô Borges, em 1981) condensa vários dos princípios que vimos apontando. $\mathrm{O}$ eu lírico, transmutado em nuvem, convida o ouvinte à fuga, à mudança, à viagem, ao movimento: "Se você quiser, eu danço com você no pó da estrada / Ó poeira, ventania, se você soltar o / pé na estrada, ó poeira, eu danço com você / o que você dançar (...)". Os sucessivos enjambements são indicativos da liberdade de que goza esse "eu-nuvem" (conforme o verso "O meu nome é nuvem"); nas estrofes, em contraste com o movimento incerto da melodia principal, signo dessa promessa de liberdade, ouve-se uma base harmô- 
nica em A (Lá), imutável, como se fosse o interlocutor dessa mensagem, ainda condicionado às normas e oferecendo resistência ao convite de liberdade. Numa posição intermediária, o contrabaixo, cujo registro grave normalmente é associado, semioticamente, à atitude realista, "pé-no-chão", mas que nesse caso já ensaia alguns desenhos melódicos mais ousados, recolhendo-se, contudo, à tônica.

A decisão de se lançar à liberdade parece só chegar no refrão, quando finalmente a base se liberta desse centro de gravidade tonal (A) e segue em novas direções (Dm, Em, Am, Em); enquanto isso, o verso "Se você deixar o coração bater sem medo...", cantado sucessivas vezes e com diferentes divisões dentro do compasso, parece atestar que o processo de libertação foi consumado. A mensagem subjacente à canção se coaduna com outro lema árcade, desta vez o Carpe diem: esse eu lírico transmutado em nuvem - signo que está fortemente associado à transitoriedade - parece apelar ao interlocutor para que enxergue a transitoriedade da vida, e para que se liberte.

O caráter coletivo do Clube da Esquina encontra um desdobramento em canções que reforçam nosso parentesco com as demais nações da América Latina, seja por serem regravações de clássicos desse cancioneiro, seja pela escolha de arranjos evocativos dessas culturas. No LP ora analisado, "San Vicente" e "Dos Cruces" são as canções que estabelecem esse vínculo (laços que seriam reafirmados, no segundo disco, com as canções “Casamiento de Negros", recolhida do folclore chileno por Violeta Parra e, sobretudo, "Canción por la unidad de latinoamerica”, de Pablo Milánez e Chico Buarque). Em retrospecto, a inclusão de marcas desse cancioneiro no disco de 1972 parece ter um quê de premonitório, tendo em vista que pouco depois o Chile (em 1973) e a Argentina (em 1976) também sofreriam sob o jugo de regimes ditatoriais. Em 1986, e portanto após a abertura política no Brasil, a série televisiva "Chico \& Caetano", transmitida pela Rede Globo, dedicou um programa a Milton Nascimento, Mercedes Sosa e Pablo Milanéz (e certamente, se ainda fossem vivos, Violeta Parra e Victor Jara também teriam feito parte do encontro). 
"San Vicente", nome de uma cidade fictícia, mas claramente uma alusão ao Brasil, alude ao estado de repressão como "um sonho estranho", mas que deixa marcas nos sentidos, um "sabor de vidro e corte": "Coração americano, acordei de um sonho estranho / Um gosto vidro-e-corte / Um sabor de chocolate / No corpo e na cidade / Um sabor de vida e morte / Coração americano / Um sabor de vidro e corte". A identidade latinoamericana, expressa no primeiro verso, é sublinhada, após a primeira estrofe, pelo acompanhamento flamenco ao violão, com percussão de castanholas ao fundo. É oportuno recordar que a própria formação da música popular brasileira deriva de uma mescla de elementos europeus, africanos e indígenas, como testemunha, de resto, a iconografia de época. ${ }^{1}$

O caráter coletivo a que me referi mais acima é também evidente na canção "Os Povos”. Retoma-se a metáfora da prisão (desta vez representada metonimicamente, por meio às referências a um portão de ferro e a um cadeado), que cede lugar à liberdade (metaforicamente, através das imagens tropicais, luminosas). Como a primeira faixa do disco, essa canção se inicia em registro grave e em andamento lento, pouco a pouco procedendose a uma elevação da melodia e a uma aceleração rítmica. Semioticamente, o eu lírico incita o ouvinte a uma tomada de atitude. O tom do intérprete é lamurioso; a percussão lembra o ruído de uma maria-fumaça, marcando o andamento. Interessante notar que essa percussão não é executada por um instrumento musical; se nos ativermos a esse elemento, perceberemos que se trata de um intérprete que simula, com a boca, o ruído de um chocalho. Essa dissimulação é elemento-chave dentro da proposta libertária do disco, uma obra que lança mão, sistematicamente, das camuflagens para que possa veicular sua mensagem.

As estrofes, de caráter contido, deságuam num refrão em que os acordes tensionados dão lugar a acordes contínuos, abertos (em $7^{\mathrm{a}}$ maior), e onde se repetem as imagens

\footnotetext{
${ }^{1} \mathrm{Na}$ célebre tela "Dança do Lundu" (1835), de Johann Moritz Rugendas, é possível identificar um dos personagens alçando seus braços para o alto e tocando castanholas, sem falar, claro, nos vários cronistas que reproduziram cenas da música negra e da música indígena, desde Hans Staden e Jean de Léry ao próprio Rugendas ("Batuque”), Jean-Baptiste Debret ("Tocador de Berimbau"), Spix e Martius ("Batuque") etc.
} 
luminosas relacionadas à felicidade: "Ah, um dia, qualquer dia de calor é sempre mais um dia de lembrar a cordilheira de sonhos que a noite apagou". O desfecho dessa canção, em que o intérprete solta um brado incontido de "Meu povo, meu povo!" (confirmando, mais uma vez, o caráter coletivo dessa obra) é sublinhado por acordes desferidos ao violão com violência. O executante deixa soar não apenas as cordas que formam o acorde, mas também cordas "soltas" que, no conjunto, destoam harmonicamente. São justamente cordas não pressionadas pela mão do executante, a que chamamos de cordas "soltas", por extensão, "livres".

\section{Clube da Esquina 2 (1978)}

Seis anos após Clube da Esquina, encontramos no LP duplo de 78 uma coerência com os mesmos princípios estéticos e políticos sinalizados no disco de estreia, embora aqui as metáforas luminosas de um Brasil tropical já sejam indicativas de um cenário de préabertura política e de fim do regime militar.

A vibrante faixa de abertura, "Credo", se inicia com um coro litúrgico entoando "San Vicente", como que anunciando uma retomada do projeto de 1972. Em efeito de fadein, e num arranjo de gosto andino (flautas, charango e violão, sublinhados por um baixo de linha melódica bem desenhada, influência do rock progressivo inglês), entra a canção propriamente dita, cujo apelo político, numa fase pré-Anistia, já não se mascarava sob alusões turvas, mas se revelava em metáforas de decifração óbvia:

Caminhando pela noite de nossa cidade / Acendendo a esperança e apagando a escuridão - vamos! / Caminhando pelas ruas de nossa cidade - viver! / Derramando a juventude pelos corações / Tenha fé no nosso povo que ele resiste / Tenha fé no nosso povo que ele insiste / E acorda novo, forte, cheio de paixão - Vamos! / Caminhando de mãos dadas com alma nova - Viver! / Semeando a liberdade em cada coração / Tenha fé no nosso povo que ele acorda / Tenha fé no nosso povo que ele assusta. 
O tom afirmativo alastra-se pela canção afora, sem que haja passagens que o contrariem, nem no plano da letra, nem no musical; versos como "Aquecidos pelo sol que vem depois do temporal" nos remetem, mais uma vez, à luminosidade dos trópicos, um traço já cantado por Caetano Veloso em "Alegria, alegria” e pelos Tropicalistas em seu discomanifesto de 1968. Mas, ao contrário do grupo de Gil e Caetano, que teriam de esperar longos anos para ver concretizado esse seu desejo, o grupo mineiro já podia cantar a liberdade a plenos pulmões.

"Ruas da Cidade" é uma homenagem à cidade de Belo Horizonte, berço do “Clube”. É um desfile de nomes de tribos indígenas, que batizam várias ruas do centro da capital mineira, e nesse processo reforça-se a preocupação dos componentes do Clube da Esquina em afirmar nossa identidade miscigenada. O processo de composição minimalista, em que a sintaxe se reduz ao mínimo em favor de um inventário de signos, potencializa o efeito da composição.

A afirmação da identidade indígena também perpassa "Testamento", em que um eu lírico índio distribui recomendações aos seus para o dia em que morrer. Além de inaugurar uma consciência ecológica ("Cuidem bem de minha casa”), reforça a ideia de transitoriedade e deslocamento na imagem das cinzas que são jogadas no rio (e o rio, sabemos desde Heráclito, é um signo de mutação).

"Paixão e fé", de Tavinho Moura e Fernando Brant, confere ao disco um tempero de identidade inegavelmente mineira, ressaltando a religiosidade desse povo. A cena descrita é a de uma procissão, com sinos convocando os fiéis e ruas enfeitadas, para que "cantem a ressurreição”, momento em que esse povo sofrido “(...) Põe de lado a sua dor / (...) Esquece a sua paixão / Para viver a do Senhor".

Os versos iniciais apresentam-nos uma perfeita conjunção entre letra e melodia: cada sílaba é cantada numa altura diferente, simulando os sons de um carrilhão: "Já bate o sino, bate na catedral (...)”. A partir daí a melodia se estabiliza e inicia-se a procissão, num crescendo que deságua no refrão, cantado, como convém à situação descrita, em coro: "Velejar, velejei / No mar do Senhor / Lá eu vi a fé e a paixão / Lá eu vi a agonia da barca 
dos homens". Além de os versos conterem signos de deslocamento e métricas distintas, eles são interpretados numa linha melódica pouco previsível e bastante acidentada (em especial o último verso), o que pode ser lido como uma metáfora das provações que o homem tem de enfrentar em sua caminhada.

Após alguns volteios ascendentes e descendentes, a melodia retorna ao centro tonal, como que sinalizando para os fiéis que se mantenham firmes em suas convicções, pois por maiores que sejam os percalços, a mão firme de Deus guiará essa "barca dos homens" de volta ao seu porto - ou, para retomarmos uma canção já comentada, de volta ao seu cais. Essa referência à barca, mesmo inserida numa moldura bíblica e, portanto, alegórica, reforça a centralidade do motivo do deslocamento nas composições do grupo, por extensão, de fuga de um lugar ou situação para outro.

“Olho D’água”, de Paulo Jobim e Ronaldo Bastos, retoma o princípio composicional do Ubi Sunt (Onde estão?) como metáfora para a morte. Manuel Bandeira, a propósito, utiliza esse recurso com maestria no poema "Profundamente":

\section{(...) Quando eu tinha seis anos}

Não pude ver o fim da festa de São João

Porque adormeci

Hoje não ouço mais as vozes daquele tempo

Minha avó

Meu avô

Totônio Rodrigues

Tomásia

Rosa

Onde estão todos eles?

Estão todos dormindo

Estão todos deitados

Dormindo

Profundamente.

(BANDEIRA, [s.d.], p. 139-140)

Executada num andamento dolente, a canção se inicia com signos de deslocamento, nos versos: "E já passou, não quer passar / E já choveu, não quer chegar / E me lembrou 
qualquer lugar / E me deixou, não sei que lá”. Segue-se um desfile de nomes possível de ler lido como uma denúncia velada aos desaparecidos políticos: “(...) Caiu no mar, Nena / Pipo, cadê você? / Dora, cadê você? / Pablo, Lilia cadê você? (...) Caiu no mar, Pedro / Chico, cadê você? Lino, cadê você? / Zino, Zeca, cadê você?”. Esse chamamento é entrecortado por sintagmas (que até podem ser topônimos), vários dos quais fazem alusão à água, como "Beira Rio”, Poço Fundo", "Cachoeira”, “Água Fria”, "Sumidouro” e aquele que nomeia a canção, "Olho d’Água”. O coro, por sua inflexão lamuriosa, sugere-nos um grupo de carpideiras, o que confirmaria a leitura de que todos os personagens listados estão mortos. Elas entoam os nomes de lugares numa ladainha monocórdia, até que a canção se encerra, com um acorde em modo menor e o melancólico timbre de um cello.

A canção "Léo" parece ter sido inspirada nas capas dos dois LPs. Naquela do disco de 72, dois meninos, um negro e um branco, fitam a câmera, sentados num barranco. Um deles come um pedaço de pão. No documentário História do Clube da Esquina - A MPB de Minas Gerais, dirigido por Bel Mercês e Leticia Gimenez, o fotógrafo Carlos da Silva Assunção Filho - Cafi - explica que a foto foi tirada na estrada entre Minas e Rio e que não se pensou - pelo menos a princípio - em se representar Lô Borges e Milton Nascimento. No entanto, ele nos chama a atenção para a coloração da estrada e da vegetação, que lembra o verde-amarelo de nossa bandeira, e a presença de um arame farpado que, nessa leitura, sugere a repressão ditatorial. Os meninos, alheios a essas preocupações “de adultos”, são a síntese do despojamento e da alegria infantis: sujos de terra, parecem felizes.

A capa do LP de 78, por sua vez, traz vários meninos, de costas para a câmera, curvando-se por sobre uma mureta, para olharem algo que não podemos sondar. Os pés descalços e sujos são índices de uma liberdade que os compositores do disco só experimentam através das canções. O efeito da canção "Léo" é potencializado pelo fato de esses dois temas se tangenciarem - o da criança e de sua felicidade, encontrada nas pequenas coisas, por um lado, e o da fuga, da viagem, do deslocamento, por outro:

Um pé na soleira e um pé na calçada, um pião

Um passo na estrada e um pulo no mato

Um pedaço de pau 
Um pé de sapato e um pé de moleque

Léo (...)"

De resto, o arranjo grandiloquente, elaborado por Wagner Tiso e executado por uma orquestra, serve de contraponto à simplicidade do tema.

O motivo da água - mais um signo de deslocamento - já percebido nas duas composições comentadas anteriormente, é retomado em "Canoa canoa". Assim como em "Ruas da Cidade", uma vez mais é exaltada a identidade indígena, por meio de referências ao ambiente da selva, pela inserção de instrumentos e signos sonoros evocativos desse ambiente (os bambus e o canto de pássaros) e pelos peixes, cujos nomes são de origem indígena: Grumatá, Piracará, Pira-andirá, Jatuarana, Taiabucu, Piracanjuba.

A composição de fechamento ao álbum, "Que bom, amigo", é um desdobramento do interlúdio instrumental que ouvíramos ao final de "Cais", do disco de 72. O tom sombrio do arranjo anterior, executado em andamento mais lento, torna-se desta vez mais leve por ser mais acelerado, em conformidade com uma letra afirmativa, que celebra a amizade e a liberdade de poder demonstrá-lo - como por exemplo, no retorno emocionado de um amigo que volta do exílio:

Que bom, amigo

Poder saber outra vez que estás comigo

Dizer com certeza outra vez a palavra amigo

Se bem que isso nunca deixou de ser.

\section{Conclusão}

Os discos em tela são, como disse, marcos da música popular feita no Brasil, em especial o LP de 1972, que sem nenhum favor figura ao lado de discos como Chega de Saudade (João Gilberto, 1959), Tropicalia ou Panis et Circensis (Caetano, Gil et al, 1968) e Acabou Chorare (Novos Baianos, 1972).

A despeito da diversidade composicional das obras em tela - um reflexo das contribuições do grupo heterogêneo que participou desses projetos -, existe uma coerência interna que nos permite enxergar alguns fios condutores em ambos os LPs. Um deles, e o 
que mais me interessou nesta análise, é o tema do deslocamento, da transitoriedade e, por extensão, da liberdade e da descoberta de novos horizontes - uma forma sui generis de canção de protesto.

Ressalte-se que esse leitmotif não se restringiu às letras, uma vez que os músicos lograram revestir as várias histórias relatadas com roupagens sonoras as mais variadas. O resultado desse processo, como pretendi demonstrar, é uma rica jornada lítero-musical em que desfilam vários dos elementos que compõem o mosaico cultural brasileiro.

\section{ESCAPING SOMEWHERE ELSE: THE “CORNER'S CLUB”, A POETICS OF MOVEMENT}

ABSTRACT: The paper intends to be a bird's eye view over the two collective albums Clube da Esquina (1972) and Clube da Esquina 2 (1978), which had as figureheads Milton Nascimento and Lô Borges. Written and launched through the Military Dictatorship (1964-1985), the albums are marked by a poetics which highlights the use of metaphors and other figures of speech that disguise direct criticisms to the regime. In this paper I make a lyrical and musical analysis of some of the songs that are in both albums, giving special attention to the allegories of displacement and of movement, which not only make veiled criticisms to the adverse political situation, but also suggest a relation with the Arcadian poets' Fugere urbem.

KEYWORDS: “Corner's Club”; Protest song. Brazilian Popular Music. Milton Nascimento. Lô Borges.

\section{REFERÊNCIAS}

BANDEIRA, Manuel. Estrela da vida inteira. São Paulo: Círculo do Livro, [s.d.].

BORGES, Márcio. Os sonhos não envelhecem: histórias do Clube da Esquina. São Paulo: Geração Editorial, 1997.

DOLORES, Maria. Travessia: a vida de Milton Nascimento. Rio de Janeiro: Record, 2005.

FORTES, Liana (org.) Fernando Brant. Rio de Janeiro: Editora Rio / Universidade Estácio de Sá, 2005. Coleção "Gente”.

História do Clube da Esquina - A MPB de Minas Gerais. Direção Bel Mercês e Leticia Gimenez. Apoio: TV PUC / TV Cultura, 2008. 45 min. Disponível em: https://www.youtube.com/watch?v=SACaczm6gA4. Acesso em 4 mai 2019. 
"Lô Borges fala sobre o mítico 'disco do tênis"'. Entrevista de Lô Borges à jornalista Daniella Zupo. Disponível em: https://www.youtube.com/watch?v=wrLBbFJqSxQ. Acesso em 4 mai. 2019.

NASCIMENTO, Milton; BORGES, Lô. Clube da Esquina. EMI, 1994 [1972]. 1 CD (64:24min): digital, estéreo. 830429-2.

. Clube da Esquina 2. EMI, 1994 [1978]. 2 CDs (42'28min / 38:02min): digital, estéreo. 791606-2.

O som do vinil: Clube da Esquina. Disponível em:

https: / /www.youtube.com/watch?v $=$ n8RT2KkHK5w. Parte 1. 27:06min. Acesso em 4 mai. 2019.

Recebido em: 22/05/2019.

Aprovado em: 30/07/2019. 